\title{
Congenital Vena Cava Abnormality
}

National Cancer Institute

\section{Source}

National Cancer Institute. Congenital Vena Cava Abnormality. NCI Thesaurus. Code C98886.

An abnormality of the superior or inferior vena cava that is present at birth.

Representative examples include persistent left superior vena cava, absence of infrarenal inferior vena cava, or absence of the entire inferior vena cava. 